\title{
Nutrition and Behavior as it Applies to Systemic and Ocular Disease 2008
}

\author{
BY LARRY J. ALEXANDER, OD, FAAO
}

\section{Introduction and the Importance of Diet}

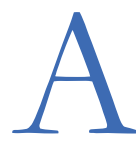
fter several years in the practice of health care and watching an increase in immune-complex disorders, inflammatory disorders and degenerative diseases, I believe it is time for the health care community to initiate Cross-Talk. One recent study reports a healthy lifestyle combining not smoking, a healthy weight, a healthful diet including moderate alcohol consumption, and daily exercise reduced ischemic strokes by approximately half in both men and women. ${ }^{1}$ The transfer of this critical information to all health care providers is important to the long-term health of all. This represents the essence of the Cross-Talk.

Most specialties and sub-specialties are publishing discoveries within their own journals without communicating those findings to other disciplines in spite of the fact that the results may have direct impact on the management of a different body system. As an example, how many health care practitioners who treat herpes zoster have read:

"Herpes zoster. The treatment and prevention of neuralgia with adenosine monophosphate. ${ }^{2}$

Thirty-two adults were enrolled in a randomized, placebo-controlled double-blind trial of intramuscular injections of gel-sustained adenosine monophosphate (AMP) given three times a week for up to four weeks for acute herpes zoster. Adenosine mono phosphate moderately reduced the pain soon after the start of treatment, decreased desquamation time, and promoted faster healing of the skin than placebo treatment. Adenosine monophosphate treatment reduced virus shedding and cleared the virus faster than in placebo-treated subjects. At the end of the initial four-week treatment period, 88\% of AMP-treated patients were pain free, as opposed to only $43 \%$ in the placebo group. After four weeks, all patients who had not recovered from pain started receiving AMP treatment without breaking the code. All these patients recovered from pain within three weeks after initiation of treatment. No recurrence of pain or lesions was experienced from three to 18 months after the end of treatment. Adenosine monophosphate, a natural cellular metabolite, showed no side effects or toxicity during and after the treatment."

The eye provides an excellent model to illustrate the impact of one discipline on another. Cardiologists are well aware of the potential of some nutritional supplements in the management of vascular disorders. Vascular alteration to the eye results in a number of disorders including glaucoma and macular degeneration. Why then would an eye care professional not want to realize the ongoing thought process in cardiology. Dermatology realizes that Coenzyme Q10 (CoQ10) levels reflect the likelihood for the progression of malignant melanoma, one of the more dreaded ocular conditions.

Of particular interest is the behavior of our society in the creation of nutritional deficiencies. Poverty, drug side effects, drug abuse, alcoholism, gastric bypass (bariatric surgery), fad diets, and just ignorance may be opening a door to the genesis of an entirely new set of nutritionally-based diseases and disorders. A question that we all must ask in relation to the work-up of any ocular disease patient must include nutritionally-related issues. ${ }^{3}$ The decreased survival of AREDS participants with Age-Related Macular Degeneration (AMD) and cataracts suggests that these conditions may reflect systemic rather than only local processes. ${ }^{4}$ Vitamin A deficiency at the least may become an issue associated with fat mal-absorption associated with bariatric surgery ${ }^{5}$ which will then impact directly on the genesis of dysfunctional tear syndrome. Vitamin B12 and folate deficiency is also related to mal-absorption and is well known to create ocular side effects with a strong relationship to hyperhomocysteinemia which represents a major cardiovascular threat. ${ }^{6-9}$ In spite of a purportedly healthy diet in the US $10 \%-14 \%$ of Americans 
have a vitamin $\mathrm{C}$ deficiency, ${ }^{10}$ and up to $15 \%$ of adults over 60 years of age have laboratory evidence of B12 deficiency. ${ }^{6}$ Treatment of the majority patients with these readily obtainable nutrients involves basic diet good sense or supplementation as well as exercise and general modification of behavior including cessation of smoking and minimizing the use of alcohol. It continues to amaze that patients believe in the magic bullet. A recent study points out that despite eating a diet rich in omega-3 fatty acids, Alaskan Eskimo patients are developing subclinical atherosclerosis at an early age, likely due in large part to heavy smoking. ${ }^{11}$ The thrust of the message in this discussion is that synergism is key rather than an isolated monotherapy approach in the management of most chronic, neurodegenerative, and inflammatory disorders. Modulation (balance) is the critical watchword in the approach to the management of health in most individuals while minimizing risk. Radical behavior or unbalanced therapy can and will create far more harm than good. Exercise potentiates effects and combinant therapies represent the theme of recent "eurekas." Regular exercise and consuming long-chain n-3 fatty acids (FAs) from fish or fish oil can independently improve cardiovascular and metabolic health, but combining these lifestyle modifications may be more effective than either treatment alone. (Am J Clin Nutr 2007;85:1267) There is no magic pill, but rather a mental set and lifestyle that set the tone for maximizing health. While we should expect everyone to modulate their behavior to maximize their health it just will not happen so we must arm ourselves to become "personal health advisors" to our patients. A recent review study corroborates this stating that healthy lifestyle habits include not smoking, maintenance of optimal BMI, moderate alcohol consumption, and daily exercise. In men and women, maintenance of healthy lifestyle habits is associated with an $80 \%$ reduction in the risk for stroke. ${ }^{1}$

Another critical issue regarding supplementation is that the health care provider is often unaware of the patient's use of non-pharmaceutical products. Vitamin E and Gingko biloba may not be reported in patients using blood thinners. Prothrombin times (PT) will definitely be affected by the utilization of many supplements leading to the possibility of increased bleedability. In a survey conducted in 1999, about $49 \%$ of adult Americans were estimated to have used herbal products during the previous year. It has been documented that as many as $31 \%$ of the patients who use herbal supplements do so in conjunction with prescribed drugs and about $70 \%$ of these patients do not regularly report the use of these products to their health care providers. ${ }^{12-13}$

Another enlightening report speaks to the use of complementary medicine use in cancer survivors. It is reported that prayer and spiritual practice were the most prevalent methods, reported by $61.4 \%$ of survivors. This was followed by relaxation $(44.3 \%)$, faith and spiritual healing (42.4\%), nutritional supplements and vitamins (40.1\%), meditation (15\%), religious counseling $(11.3 \%)$, massage $(11.2 \%)$, and support groups $(9.7 \%)$. Hypnosis was least likely to be used $(0.4 \%)$, and biofeedback therapy $(1.0 \%)$ and acupuncture/acupressure (1.2\%) were used only slightly more often. ${ }^{14}$

One critical issue to address is the validity of claims that evolve from scientific studies. This discussion is intended to be scientifically-based to provide the reader with an understanding of the potential of behavioral issues as they relate to the genesis of ocular and systemic disorders. With that in mind be cognizant of the fact that numerous claims by a plethora of studies have yet to be substantiated. The difficulty in developing incontrovertible evidence stems from the complexity of human trials. Extrapolation of some of the concepts of basic research to clinical application is possible, but guarded optimism is the watchword until clinical trials support results. Any analysis of published reports must be tempered by the structure of the study. Peter McDonnell in a recent editorial in Ophthalmology Times February 15, 2006, discusses "Are you skeptical of the latest peer-reviewed results?" Dr. McDonnell cites an article by Ioannidis regarding the fact that Ioannidis reviewed 49 "important" research articles published in top medical journals between 1990 and 2003 and subsequently cited 1000 times. Over $33 \%$ of these articles were found to be wrong." 15-17 Critical review of new ideas prior to translation of the information to the general health care delivery team is critical in the evolution of any educational model. Increased fraud in publication of trials also seems to be on the increase with printed retractions occurring far after the potential impact of the results ${ }^{18-19}$ as well as an excess of apparently significant clinical findings. ${ }^{20}$ One Canadian study provided an 
interesting commentary on industrysponsored research on prostaglandin medications. They found that industry-funded studies were significantly more likely $(19 / 27$ studies $=70 \%)$ to have abstract conclusions that did not match the actual reported main outcomes of the study than were non-industry-funded investigations $(2 / 12=17 \%, P=.002)$. Conclusions of the abstracts in industry-funded studies were supportive of the company's drug $89 \%$ of the time. ${ }^{21}$

With the caveat of guarded optimism the investigation of the literature regarding cross-talk may be initiated.

\section{Diet That Supports Anti- In囚ammation, Neuropro- tection and Overall Ocular Health}

The eyes are truly the window to both the soul and functioning of the body. All aspects of health are ultimately reflected in the health of the eye but the direct cause-effect relationship is evasive because of the cumulative effect of one's actions. Diet and diets both affect the health of the eyes. An abusive diet, drug interactions, and toxicities create health issues within the cardiovascular, endocrine and neurological systems that reflect in ocular function. Likewise radical diets and bariatric surgery rob the body of essential nutrients to promote proper function. This discussion will but touch the high points of diet, behavioral modification and supplementation but will speak to the importance of a coordinated effort in preventing and managing systemic and thus ocular disorders.

Excessive weight and obesity in concert with an inappropriate diet loom as a constant threat to both systemic and ocular health. ${ }^{22-23}$ Morbidity and mortality are both affected by diet with a prudent approach being to maintain your weight at a reasonable level while concurrently consuming health-sustaining nutrients. There are studies linking obesity to macular degeneration. ${ }^{24}$ In one report overall and abdominal obesity increased the risk for progression to advanced AMD, and more physical activity tended to decrease risk. ${ }^{25-26}$ Ironically there is also increased risk should the patient be too thin implying the influence of malnourishment. ${ }^{27}$ Another recent report suggests that in Latinos cardiovascular risk factors may play a role in advanced AMD. ${ }^{28}$ This should be of no surprise since Richer's original work demonstrated that cardiovascular risk factors including serum $\mathrm{Fe}$ levels contributed to the progression of AMD. ${ }^{29-30}$ The other risk factors often associated with heart disease such as smoking and altered blood composition are also modifiable in our patient base. ${ }^{31-35}$ Reports also attest to the fact that obesity is actually related to a decrease in macular pigment levels that may be attributable to an inherent competition with adipose tissue. ${ }^{36-38}$ Serum levels of lutein and zeaxanthin are the true measures of efficacy of the protective effects of diet and both levels are measured lower with obesity and diabetes. ${ }^{36}$ All of these studies still do not absolutely indicate the need for diet control from a scientific standpoint, but studies point to the necessity for cessation of smoking in minimizing the risk for AMD. ${ }^{39}$

From the standpoint of cataract development there has been much discussion regarding diet. While very specific, some studies show a link of metabolic syndrome with the genesis of cataracts. ${ }^{40-41}$ It appears that there is a link between oxidative stress and cataract formation with smoking again being implicated. ${ }^{42}$ In general it also appears that obesity is a positive marker for the increased likelihood of cataract formation but a bit unpredictable based on the type of cataract. ${ }^{43-45}$ With a higher Body Mass Index (BMI), abdominal obesity, and diabetes, patients develop a higher incidence of cortical and posterior sub-capsular cataracts. ${ }^{46-47}$

The link to diabetes and obesity (most specifically the metabolic syndrome) is incontrovertible. ${ }^{48-51}$ Metabolic syndrome denotes a common cluster of naturally connected risk factors including obesity, elevated blood pressure, insulin resistance, dyslipidemia, proinflammatory state and prothrombotic state. This scenario (the metabolic syndrome) has the potential to lead to multiple retinal vascular flow issues within the eye. ${ }^{52}$ The link to diabetic retinopathy is more circumspect but studies have linked retinal microvasculopathy to metabolic syndrome. ${ }^{49,53}$ Inhibition of inflammatory mediators is likewise implicated in minimizing diabetes risks ${ }^{54}$ and can be achieved by dietary modification. A diet designed to address the metabolic syndrome may be the direction to go to minimize the risk of diabetic retinopathy, but clinical trials must corroborate this conclusion. Additionally one must address other situations that may increase oxidative stress and decrease oxygenated blood supply to the eye such as smoking and sleep apnea. 
has not demonstrated a consistent reduction in the risk for stroke associated with coffee or tea consumption. One study suggests that higher levels of coffee and tea consumption can reduce the risk for cerebral infarction among male smokers but not risk rates of intracranial hemorrhage. ${ }^{78}$

- When paired with a high-glycemic-index meal, cinnamon slows gastric emptying and reduces postprandial glucose excursion.

- Nuts also slow gastric emptying and can reduce the impact of high-glycemic-index carbohydrates by as much as half. Nuts also reduce postprandial oxidative protein damage, and consumption of nuts at least 5 times weekly can reduced the risks for coronary artery disease and diabetes by $20 \%$ to $50 \%$. Eat approximately 1 handful of nuts daily (using a closed fist), consumed with vegetables, grains, berries, or other fruits.

- Vinegar can reduce postprandial glycemia and promotes satiety. Eat salad daily, consisting of leafy greens with dressing of vinegar and virgin olive oil.

- Lean protein reduces postprandial glucose excursion and improves satiety. Such protein includes egg whites, game meat, skinless poultry breast meat, and whey protein or other nonfat dairy protein. At all 3 meals, consume lean protein.

- Drinking 0.5 to 1 alcoholic drink per day for women and 1 to 2 alcoholic drinks per day for men can reduce cardiovascular risk, and 1 to 2 drinks before a meal can reduce postprandial glucose and insulin levels. However, higher levels of drinking can impair glucose metabolism.

- Exercise acutely lowers glucose and triglyceride levels in a dosedependent fashion.Perform physical activity for at least 30 minutes or more daily, of at least moderate intensity.

- Maintain normal weight and avoid overweight or obesity. Waist circumference should be less than one half of height in inches.

It has been demonstrated that a low glycemic index diet is beneficial for both weight loss and lipid profiles. ${ }^{79}$ Additionally women in the highest quintile of consumption of a high-fat, low-fiber diet had an increase in the relative risk of developing colon cancer of 1.46 compared with those in the lowest quintile. However, consumption of a high-fiber and healthy protein diet was associated with a trend toward reduced rates of colon cancer. Diet did not significantly affect the risk for rectal cancer. ${ }^{80}$

In a perfect world where we all ate the Paleolithic diet, exercised, maintained the proper weight and did not consume any substances with potential toxicity, supplementation would be totally unnecessary. However, the world is less than perfect and even the most well-meaning are faced with less than optimal lifestyles, therefore there must be some attention paid to reminders and supplementation. It is also critical that with any of these considerations, potential toxicities and interactions must be addressed.

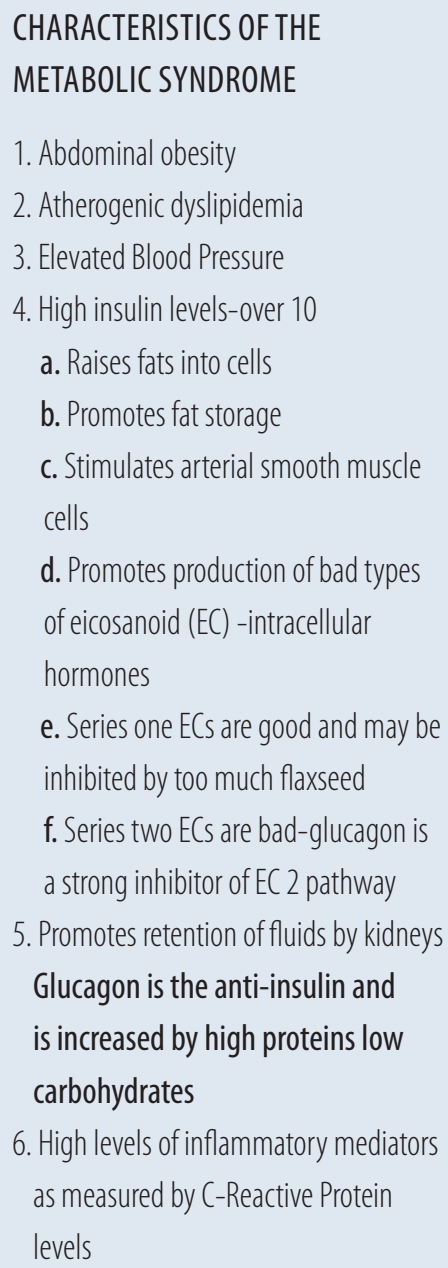

6. High levels of inflammatory mediators as measured by C-Reactive Protein levels

Part two of this series will start to address the reported benefits of specific nutrients and supplements.

Dr. Alexander receives no reimbursement from any nutritional supply company. He serves as an advisor on the Biosyntrx board for no remuneration. He is the Director of Clinical Education for Optovue, Inc, a digital imaging company, which produces the RTV ue. 


\section{References:}

1. CME Author Lie D. Overall healthy lifestyle significantly reduces stroke risk. August 11 Online First issue of Circulation. Medscape CME August 15, 2008.

2. Sklar SH, Blue WT, Alexander EJ, et al. Herpes zoster. The treatment and prevention of neuralgia with adenosine monophosphate. JAMA 1985;253:1427-30.

3. Kullman G, Bennett JL, Mandava N, Kahook M. Nutritional Deficiencies. Glaucoma Today 2007;5:33-35.

4. AREDS Report No. 13 AREDS Research Group associations of mortality with ocular disorders and an intervention of high-dose antioxidants and zinc in the Age-Related Eye Disease Study. Arch Ophthalmol. 2004;122:716726.

5. Spits Y, De Laey JJ, Leroy BP. Rapid recovery of night blindness due to obesity surgery after vitamin A repletion therapy. Br J Ophthalmol. 2004;88:583585.

6. Andràs E, Affenberger S, Vinzio S, et al. Food-cobalimin malabsorption in elderly patients: clinical manifestations and treatment. Am J Med. 2005;118:11541159.

7. Hvas A, Nexo E. Diagnosis and treatment of vitamin $\mathrm{B}_{12}$ deficiency - an update. Haematologica. 2006;91:15061512.

8. Sadun AA. Metabolic optic neuropathies. Semin Ophthalmol. 2002;17:29-32.

9. Pfeiffer CM, Caudill SP, Gunter EW, et al. Biochemical indicators of B vitamin status in the US population after folic acid fortification: results from the National Health and Nutrition Examination Survey 1999-2000. Am J Clin Nutr. 2005;82:442-450.

10. Hampl JS, Taylor CA, Johnston CS. Vitamin $C$ deficiency and depletion in the United States: the Third National Health and Nutrition Examination Survey, 1988 to 1994. Am J Public Health. 2004;94:870-875.

11. Cutchins A, Roman MJ, Devereux RB, et al. Prevalence and correlates of sub-clinical atherosclerosis in
Alaska Eskimos: The GOCADAN study. Stroke 2008; DOI:10.1161/ STROKEAHA.108.519199. Available at: stroke.ahajournals.org.

12. Wirth JH, Hudgins JC, Paice JA. Use of herbal therapies to relieve pain: A review of efficacy and adverse effects. Pain Mang Nurs 2005;6:145-167.

13. Abebe 2002. Abebe W. Herbal medication: Potential for adverse interactions with analgesic drugs. Journal of Clinical Pharmacy \& Therapeutics 2002;27:391-401.

14. Gansler T, Kaw C, Crammer C, Smith T. A population-based study of prevalence of complementary methods use by cancer survivors: a report from the American Cancer Society's studies of cancer survivors. Cancer 2008;113:1048-1057.

15. Montori VM, Devereaux PJ, Adhikari NK, et al. Randomized trials stopped early for benefit: a systematic review. JAMA 2005, 294:2203-2209

16. Ioannidis JP: Contradicted and initially stronger effects in highly cited clinical research. JAMA 2005, 294:218-228.

17. Ioannidis JPA. Limitations are not properly acknowledged in the scientific literature. J Clin Epidemiol 2007;60:324-9.

18. Trikalinos NA, Evangelou E, Ioannidis JP. Falsified papers in high-impact journals were slow to retract and indistinguishable from nonfraudulent papers. J Clin Epidemiol 2008;61:464-470.

19. Ioannidis, JP. Effect of the Statistical Significance of Results on the Time to Completion and Publication of Randomized Efficacy Trials. JAMA 1998;279:281-286.

20. Ioannidis JP, Trikalinos TA. An exploratory test for an excess of significant findings. Clin Trials 2007;4:245-253.

21. Program and abstracts of the Association for Research in Vision and Ophthalmology 2008 Annual Meeting; April 27-May 1, 2008; Fort Lauderdale, Florida. Abstract 1219.

22. Cheung N, Wong TY. Obesity and eye diseases. Survey of Ophthalmology 2007; 52: 180-95.

23. Everitt AV, Hilmer SN, Brand-Miller JC, et al. Dietary approaches that delay Age-Related diseases. Clin Interv Aging 2006;1:11-31.

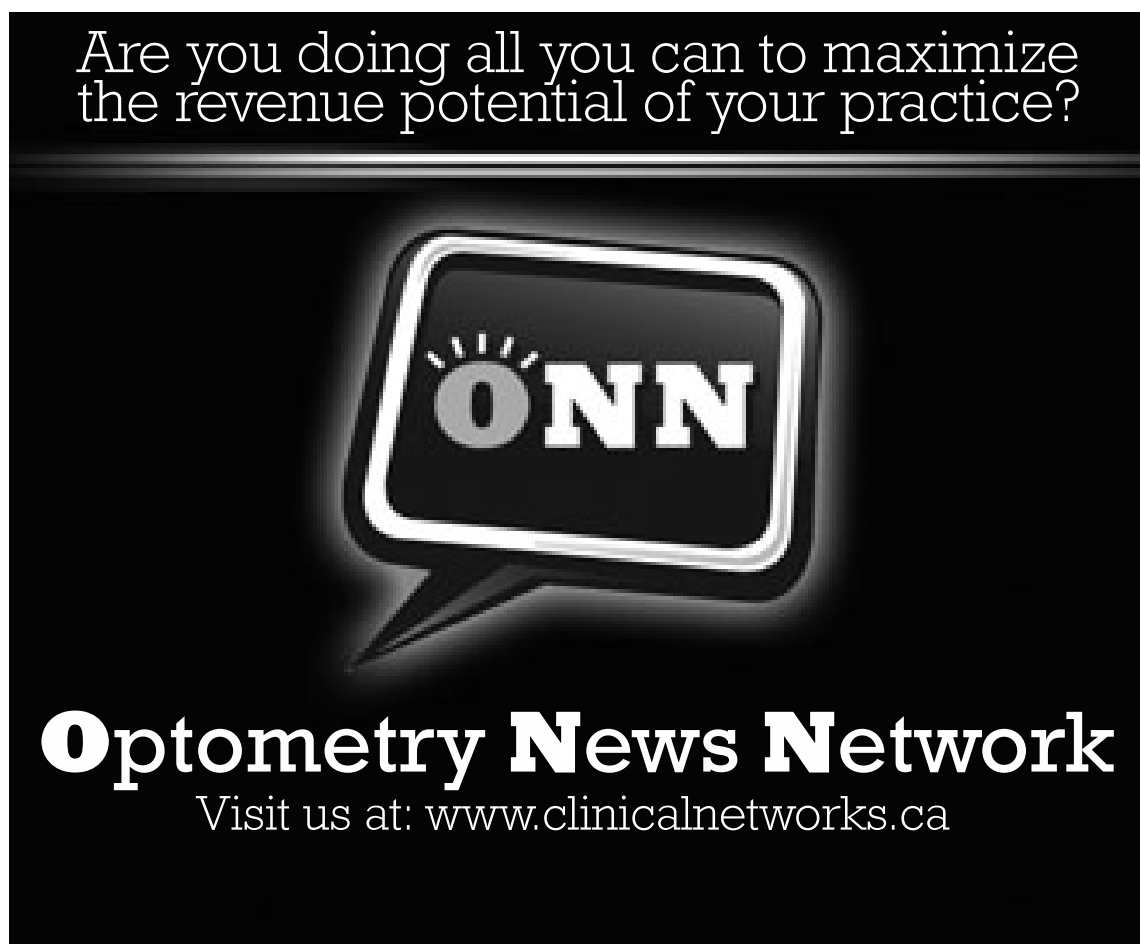


24. Santos LP, Dinez JR, Leao AC, Sena MF. Age-related Macular Degeneration: analysis in two ophthalmological centers in Pernambuco-Brazil. Arq Bras Oftalmol 2005;68:229-233.

25. Seddon JM, Cote J, Davis N, Rosner B. Progression of Age-Related macular degeneration. Arch Ophthalmol 2003;121:785-792.

26. Moeini HA, Masoudpour H, Ghanbari $\mathrm{H}$. A study of the relation between body mass index and the incidence of Age-Related macular degeneration. Br. J Ophthalmol 2005;89:964-966.

27. Schaumberg DA, Christen WG, Hankinson SE, Glynn RJ. Body mass index and the incidence of visually significant Age-Related maculopathy in men. Arch Ophthalmol 2001;119:12591264.

28. Fraser-Bell S, Wu J, Klein R, et al. Cardiovascular risk factors and agerelated macular degeneration: the Los Angeles Latino Eye Study. Am J Ophthalmol 2008;145:308-316.

29. Richer S, Rudy D, Statkute L, et al. Serum iron, transferrin saturation, ferritin, and dietary data in age-related macular degeneration.Am J Ther. 2002 Jan-Feb;9(1):25-8.

30. Richer S, Devenport J, Lang JC. LAST II: Differential temporal responses of macular pigment optical density in patients with atrophic age-related macular degeneration to dietary supplementation with xanthophylls. Optometry 2007;78:213-219.

31. Clemons TE, Milton RC, Klein R, Seddon JM, Ferris FL. The Age Related Eye Disease Study Group. Risk factors for the incidence of advanced Age-Related Macular degeneration in the Age-Related Eye Disease Study (AREDS), AREDS report no. 19. Ophthalmology 2005; 112:533-539.

32. Klein R, Deng Y, Klein BEK, et al. Cardiovascular disease, its risk factors and treatment, and age-related macular degeneration: Women's health initiative sight exam ancillary study. Am J Ophthalmol. 2007;143:473-483.

33. Schaumberg DA, Hankinson SE, Guo Q, et al. A prospective study of 2 major Age-Related macular degeneration susceptibility alleles and interactions with modifiable risk factors. Arch Ophthalmol 2007;125:55-62.

34. Smith W, Mitchell P, Leeder SR, Wang JJ. Plasma fibrinogen Levels, other cardiovascular risk factors, and AgeRelated maculopathy. Arch Ophthalmol 1998;116:583-587.

35. Drobek-Slowik M, Karczewicz D, Safranow K. The potential role of oxidative stress in the pathogenesis of the age-related macular degeneration (AMD). Postepy Hig Med Dose 2007;61:28-37

36. Mares JA, LaRowe TL, Snodderly DM, et al. CAREDS Macular Pigment Study Group and Investigators. Predictors of optical density of lutein and zeaxanthin in retinas of older women in the Carotenoids in Age-Related Eye Disease Study, an ancillary study of the Women's Health Initiative. Am J Clin Nutr 2006;84:1107-1122.

37. Johnson EJ. Obesity, Lutein metabolism, and Age-Related Macular degeneration: A Web of Connections. Nutr Rev. 2005;63:9-15.

38. Hammond BR, Ciulla TA, Snodderly M. Macular pigment density is reduced in obese subjects. IOVS 2002 43: 47-50.
39. Guymer, RH, Chong EW. Modifiable risk factors for Age-Related macular degeneration. MJA 2006;184:455-458.

40. Bojarskiene F, Cerniauskiene LR, Paunksnis A, Luksiene DI. Association of metabolic syndrome components with cataract. Medicina (Kaunas) 2006;42:115-122.

41. Paunksnis A, Bojarskiene F, Cimbalas A, et al. Relation between cataract and metabolic syndrome and its components. Eur J Ophthalmol 2007;17(4):605-14.

42. Shichi H. Cataract formation and prevention. Expert Opin Investig Drugs 2004;13:691-701

43. Paunksnis A, Bojarskiene F, Cimbalas A, et al. Relation between cataract and metabolic syndrome and Its components. Eur J Ophthalmol 2007;17:605-614.

44. Navarro E, Butierrez L, Valero C, et al. Prevalence and risk factors of Lens Opacities in the Elderly in Cuenca, Spain. Eur J Ophthalmol 2007;17:29-37.

45. Kuang TM, Tsai Sy, Hsu WM, et al. Body mass index and Age-Related cataract; the Shihpai Eye Study. Arch Ophthalmol 2005;123:1109-1114.

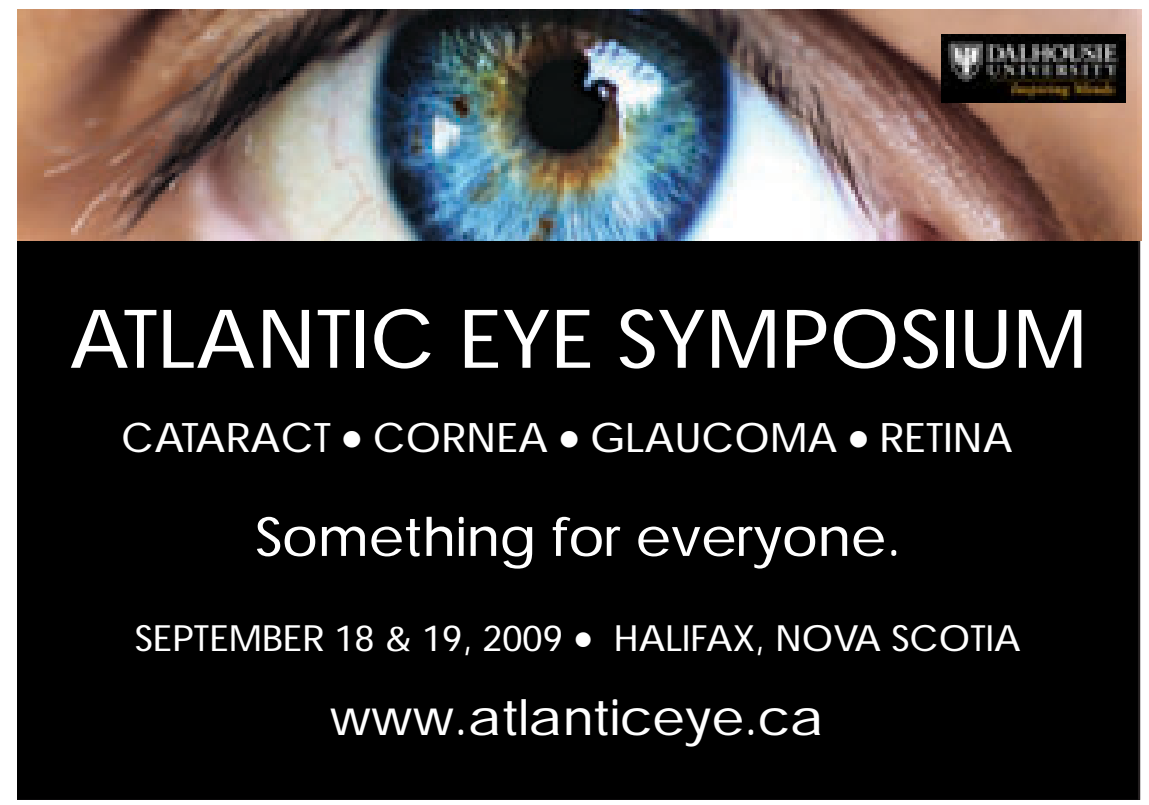


46. Hiller R, Podgor MJ, Sperduto RD, et al. A longitudinal study of body mass index and lens opacities. The Framingham Studies. Ophthalmology 1998;105:1244 50.

47. Jacques PF, Moeller SM, Hankinson SE, et al. Weight status, abdominal adiposity, diabetes, and Early Age-Related lens opacities. Am J Clin Nutr 2003 78: 400405.

48. Burnet DL, Elliott LD, Quinn MT, et al. Preventing diabetes in the clinical setting. J Gen Intern Med. 2006;21:84-93.

49. Klein BE, Klein R, Lee KE. Components of the metabolic syndrome and risk of cardiovascular disease and diabetes in Beaver Dam. Diabetes Care 2002;25:1790-1794.

50. Weber MB, Narayan KM. Prventing Type 2 Diabetes: Genes or Lifestyle? Prim Care Diabetes 2008;2:65-66.

51. Twigg SM, Kamp MC, Davis TM, et al. Prediabetes: A Position Statement From the Australian Diabetes Society and Australian Diabetes Educators Association. Med J Aust. 2007;186:461465.

52. Kosanovic-Jakovic N, Ivanovic B, Milenkovic S, et al. Anterior ischemic optic neuropathy associated with metabolic syndrome. Arq Bras Oftalmol 2008;71:62-66.

53. Wong TY, Islam FM, Klein R, et al. Retinal vascular caliber, cardiovascular risk factors, and inflammation: The Multi-Ethnic Study of Atherosclerosis (MESA). IOVS 2006;47:2341-2350.

54. Kern TS. Contributions of inflammatory processes to the development of the early stages of diabetic retinopathy. Exp Diabetes Res 2007;2007:95103.

55. Oh SW, Lee S, Park C, Kim DJ. Elevated intraocular pressure is associated with insulin resistance and metabolic syndrome. Diabetes Metab Res Rev. 2005;21:434-440.

56. Yoshida M, Ishikawa M, Kokaze, et al. Association of Life-Style with intraocular pressure in Middle-Aged and older Japanese residents. Jpn J Ophthalmol. 2003; 47;191-198.
57. Mori K, Ando F, Nomura H, et al. Relationship between intraocular pressure and obesity in Japan. Int J Epidemiol. 2000;29:661-666.

58. Lee JS, Lee SH, Oum BS, et al. Relationship between intraocular pressure and systemic health parameters in a Korean population. Clin Experiment Ophthalmol. 2002;30:237241.

59. Memarzadeh F, Ying-Lai M, Azen SP, et al. Associations with intraocular pressure in Latinos: the Los Angeles Latino Eye Study. Am J Ophthalmol. 2008;146:6976.

60. McNab AA. The eye and sleep apnea. Sleep Med Rev. 2007;11:269-276.

61. Dhillon S, Shapiro CM, Flanagan J. Sleep-Disordered breathing and effects on ocular health. Can J. Ophthalmol. 2007;42;238-243.

62. Daniels AB, Liu GT, Volpe NJ, et al. Profiles of obesity, weight gain, and quality of life in idiopathic intracranial hypertension (pseudotumor cerebri). (Am J Ophthalmol. 2007;143:635-641.

63. Cordain L, Eaton SB, Sebastian A, et al. Origins and evolution of the western diet: health implications for the $21 \mathrm{st}$ century. Am J Clin Nutr 2005;81:341-54.

64. Liu Q, Ju W, Crowston JG, et al. Oxidative stress Is an early event in hydrostatic pressure-induced retinal ganglion cell damage. IOVS 2007 48: 4580-4589.

65. Mandel S, Amit T, Reznichenko L, et al. Green Tea catechins as Brain-Permeable, natural iron chelators-antioxidants for the treatment of neurodegenerative disorders. Mol Nutr Food Res 2006;50:229-234.

66. Sutherland BA, Rahman RM, Appleton I. Mechanisms of action of green tea chatechins, with a focus on ischemiaInduced neurodegeneration. J Nutr Biochem 2006;17:291-306.

67. Zhao B. Natural antioxidants for neurodegenerative diseases. $\mathrm{Mol}$ Neurobiol 2005;31:283-293.

68. Yen WJ, Wang BS, Chang LW, Duh PD. Antioxidant properties of roasted coffee residues. J Agric Food Chem 2005;53:2658-2663.
69. Miller KB, Stuart DA, Smith NL, et al. Antioxidant activity and polyphenol and procyanidin contents of selected commercially available cocoacontaining and chocolate products in the United States. J Agric Food Chem 2006;54:4062-4068.

70. Haufschild T, Kaiser HJ, Preisig T, et al. Influence of red wine on visual function and Endothelin-1 plasma level in a patient with optic neuritis. Ann Neurol 2003;53:825-826.

71. Singleton VL, Esau P. Phenolic substances in grapes and wine, and their significance. Adv Food Res Suppl 1969;1:1-261.

72. Rhone M, Basu A. Phytochemicals and Age-jRelated eye diseases. Nutr Rev 2008;66:465-472.

73. Presenter: JoAnn Giaconi, M.D. Nutritional associations with glaucoma among older black women. American Glaucoma Society $18^{\text {th }}$ Annual Meeting. March 2008 Washington, D.C

74. Feinglos MN, Totten SE. Are you what you eat, or how much you eat? The case of Type 2 Diabetes Mellitus. Arch Intern Med. 2008;168:1485-1486.

75. O'Keefe JH, Gheewala NM, O'Keefe JO. Dietary strategies for improving post-prandial glucose, lipids, inflammation, and cardiovascular health. J Am Coll Cardiol 2008;51:249-255.

76. Karim M, McCormick K, Kappagoda CT. Effects of cocoa extracts on Endothelium-Dependent relaxation. J Nutr 2000;130:2105S-2108S.

77. Taubert D, Roesen R, Lehmann C, et al. Effects of low habitual cocoa intake on blood pressure and bioactive nitric oxide: A Randomized Controlled Trial. JAMA. 2007;298:49-60.

78. Larsson SC, Mannisto S, Virtanen MJ, et al. Coffee and tea consumption and risk of stroke subtypes in male smokers. Stroke 2008;39:1681-1687.

79. Cochrane Database Syst Rev. Published online July 18, 2007.

80. Meyerhardt JA, Niedzwiecki D, Hollis $\mathrm{D}$, et al. Association of dietary patterns with cancer recurrence and survival in patients with Stage III colon cancer. JAMA. 2007;298:754-764 